\title{
An Unified Framework to Integrate Biotic, Abiotic Processes and Human Activities in Spatially Explicit Models of Agricultural Landscapes
}

\author{
Fabrice Vinatier ${ }^{1 *}$, Philippe Lagacherie ${ }^{1}$, Marc Voltz ${ }^{1}$, Sandrine Petit ${ }^{2}$, Claire Lavigne ${ }^{3}$, \\ Yves Brunet ${ }^{4}$ and Françoise Lescourret ${ }^{3}$ \\ 1 INRA, UMR1221 LISAH (INRA - IRD - SUPAGRO), Montpellier, France, ${ }^{2}$ INRA, UMR1347 Agroécologie, Dijon, France, \\ ${ }^{3}$ INRA, UR1115 PSH, Plantes et Systèmes de Culture Horticoles, Avignon, France, ${ }^{4}$ INRA, UMR1391 ISPA (INRA - \\ Bordeaux Sciences Agro), Villenave d'Ornon, France
}

OPEN ACCESS

Edited by:

Maria Tsiafouli,

Aristotle University of Thessaloniki,

Greece

Reviewed by:

Subhrajit Saha,

Georgia Southern University, USA

Nefta Eleftheria Votsi,

Aristotle University of Thessaloniki,

Greece

${ }^{*}$ Correspondence:

Fabrice Vinatier

fabrice.vinatier@supagro.inra.fr

Specialty section:

This article was submitted to Agroecology and Land Use Systems,

a section of the journal

Frontiers in Environmental Science

Received: 24 September 2015 Accepted: 18 January 2016

Published: 02 February 2016

Citation:

Vinatier F, Lagacherie P, Voltz M,

Petit S, Lavigne $C$, Brunet $Y$ and

Lescourret F (2016) An Unified

Framework to Integrate Biotic, Abiotic

Processes and Human Activities in

Spatially Explicit Models of Agricultural

Landscapes. Front. Environ. Sci. 4:6.

doi: 10.3389/fenvs.2016.00006
Recent concern over possible ways to sustain ecosystem services has triggered important research worldwide on ecosystem processes at the landscape scale. Understanding this complexity of landscape functioning calls for coupled and spatially-explicit modeling approaches. However, disciplinary boundaries have limited the number of multi-process studies at the landscape scale, and current progress in coupling processes at this scale often reveals strong imbalance between biotic and abiotic processes, depending on the core discipline of the modelers. We propose a spatially-explicit, unified conceptual framework that allows researchers from different fields to develop a shared view of agricultural landscapes. In particular, we distinguish landscape elements that are mobile in space and represent biotic or abiotic objects (for example water, fauna or flora populations), and elements that are immobile and represent fixed landscape elements with a given geometry (for example ditch section or plot). The shared representation of these elements allows setting common objects and spatio-temporal process boundaries that may otherwise differ between disciplines. We present guidelines and an assessment of the applicability of this framework to a virtual landscape system with realistic properties. This framework allows the complex system to be represented with a limited set of concepts but leaves the possibility to include current modeling strategies specific to biotic or abiotic disciplines. Future operational challenges include model design, space and time discretization, and the availability of both landscape modeling platforms and data.

Keywords: conceptual model, human practices, interdisciplinarity, landscape, modeling procedure

\section{INTRODUCTION}

The emergence of the ecosystem service concept (Costanza et al., 1997) has ignited interest in the landscape-oriented disciplines and stressed the need for an integrated view of landscapes. As emphasized by Termorshuizen and Opdam (2009), landscapes deliver a wide range of "functions" that can be viewed as "services" when they are valued by humans. According to these authors, the study of landscape services requires an interdisciplinary approach at the landscape scale. Scientists 
from various disciplines are encouraged to cooperate in producing a common knowledge base that can be integrated into multifunctional landscape assessments.

Agricultural landscapes are of primary interest since they cover about $38 \%$ of the global landmass (FAO, 2011). Although they differ from other landscapes in that they are mainly managed for food or feed production and under strong influence of human activities (e.g., crop allocation, plowing, irrigation, fertilization, ditch digging), agricultural landscapes shelter a large range of processes, which are either abiotic (e.g., runoff, soil erosion, sedimentation and transport by air flows) or biotic (e.g., plant growth, dispersal of organisms, and biodegradation of pesticides). Each process, whether it is biotic, abiotic or human, acts at a given spatial and temporal scale and grain, and the estimation of an ecosystem function is the result of complex interrelations between a set of biotic, abiotic and human processes that need to be analyzed.

Natural processes and human activities in agricultural landscapes have been analyzed within a number of scientific disciplines such as landscape ecology (Burel and Baudry, 2003; Turner, 2005), catchment hydrology (Grayson et al., 2002; Schröder, 2006), landscape-scale pedology (Pennock and Veldkamp, 2006), and landscape agronomy (Verburg and Overmars, 2009; Benoît et al., 2012). These disciplines are built on a common "pattern-process" or "structure-function" paradigm, in which landscape patterns both impact and are impacted by the processes occurring in landscapes. They also share the use of spatially explicit models that account for the spatial variations of biotic or abiotic processes and their interactions with landscape features at different scales (Beven and Kirkby, 1979; Arnold, 1990; Tilman and Kareiva, 1997; Ovaskainen and Hanski, 2004). Indeed, spatially explicit modeling tools are useful for predicting the impact of specific and spatially distributed landscape management actions (Matthews et al., 2007). However, while sharing some common paradigms, the different disciplines have independently developed their own landscape modeling approaches. Each has considered specific landscape features and processes, and in turn has developed specific concepts for representing landscape functioning and to understand ecosystem services provided by landscapes. However, spatio-temporal boundaries of the considered processes or landscape element often differ between disciplines (for example the plot limits are different whether ecological, agronomical or pedological processes are considered). This makes it problematic to couple several abiotic and biotic processes to understand ecosystem services provided by landscapes.

In this perspective paper we suggest an explicit conceptual framework that should help modelers from different disciplines to build spatially and temporally coherent landscape representations that link biotic, abiotic and human processes before implementing their models. The framework is adapted to spatially-explicit models focusing on the impact of spatial arrangement of human practices in landscapes. It provides a generic spatial and functional representation of the main characteristics and related processes of landscapes. We illustrate the potential of this framework on an example of agroecosystem involving several interacting biotic, abiotic and human processes.
Specific questions related to the scientific and technical application of our conceptual framework are addressed in a final section.

\section{PRESENTATION OF THE FRAMEWORK}

The framework represents the landscape characteristics and processes with five generic landscape features:

1. Time-variant landscape mosaics, that are composed of Immobile Landscape Elements (ILE) such as fields, ditches, soil units, etc. ILE have a fixed position in the landscape, although their characteristics and spatial extent may change with time. They are defined by their geometry, which forms the geometry of the whole landscape, their position, and a set of properties governing the landscape processes (e.g., hydraulic conductivity and habitat attractiveness). ILE have permanent connections with other ILE, which depend on the spatial arrangements of the mosaics. The ILE properties are variable in time because they are influenced by landscape processes, human activities, and other external conditions.

2. A set of landscape processes that can be either biotic or abiotic and that may have an explicit spatial dimension (e.g., water fluxes in a landscape or insect dispersal) or not (e.g., plant growth). Landscape processes closely interact with the landscape mosaics because they are influenced by the geometry, properties and state variables of ILE (e.g., runoff is influenced by differences in soil infiltration capacity resulting from the various cultivation techniques used across the fields) and may change, in turn, the ILE and their connectivity (e.g., in the case of dispersal for overwintering insect species for which forests offer suitable habitats during winter but not during other seasons).

3. A set of Mobile Landscape Elements (MLE) that represent bodies of matter (e.g., soil material, water bodies volumes, biological individuals, or populations) whose position can vary (they circulate within and between the ILE), and whose characteristics may change with time according to landscape processes, human activities, and other external conditions. Their position and geometry can change with time within the geographical landscape structure provided by the ILE. The characteristics of MLE are described by state variables that can be quite diverse, according to the landscape modeling literature. They can be quantities, concentrations, volumes, or the geographical position of any MLE of interest, like insects or mammals taken as groups or individuals. State variables of MLE differ from previously defined properties of ILE in that (i) their variations in time are faster than those of the properties governing landscape processes (e.g., soil hydraulic conductivity varies more slowly than soil water level), and (ii) they can serve as output or input for further evaluation of landscape services.

4. A set of human activities that may interact with items 1 and 3 above. The impacts of human activities on landscape mosaics are defined by their location (e.g., a farm territory for a farmer), the induced modifications of the geometry or properties of ILE (e.g., building a ditch), and the fluxes 
of elements that they affect. Activities are also prone to modify the state variables of the MLE (e.g., irrigation increases soil water content, or pesticides applications decrease insect abundance). Conversely, the geometry and properties of ILE, as well as the status of the MLE, greatly affect human activities (e.g., farmers sow according to soil moisture and apply pesticide in response to pest abundance). Other intrinsic factors affecting human activities, such as personal characteristics of land managers, could be integrated in this component provided that they exhibit spatial or temporal heterogeneities.

5. A set of external conditions that depend on processes taking place outside or at the boundaries of the landscape, and that affect landscape processes by fixing or modifying the landscape boundary conditions. Obvious examples of external conditions are the climatic conditions or biological infestations to which the landscape is subjected.

\section{ILLUSTRATION OF THE FRAMEWORK APPLICABILITY ON AN AGROECOSYSTEM EXAMPLE}

In what follows, the conceptual framework is tested against a case study that involves (i) multiple biotic, abiotic and human processes, (ii) variations in space and time of landscape conditions, and (iii) several mutual impacts of actions and feedbacks.

We consider an agricultural landscape located in a Mediterranean area $\left(43^{\circ} 300 \mathrm{~N}, 3^{\circ} 190 \mathrm{E}\right)$. This landscape includes a variety of land uses, i.e., vineyards, annual crops, fallows and woodlands (Sluiter and Jong, 2006), different landscape infrastructures, i.e., pounds and ditches (Levavasseur et al., 2015), and a complex soil pattern (Coulouma, 2008). We focus our study on three landscape services: water erosion control (especially for the prevention of soil loss by runoff, as in David et al., 2014), water regulation (water provisioning for agriculture, see Levavasseur et al., 2012), and enhancement of remarkable biodiversity (Davies et al., 2008; Herzon and Helenius, 2008) with the provision of corresponding habitats for two endangered animal species (the common toad, Bufo bufo and the damselfly, Calopteryx virgo).

This case study can be conceptualized according to our framework, as shown in Figures 1, 2. Figure 1 provides an overview of the whole case study. Its conceptualization includes (i) a time-variant landscape mosaics composed of six ILE on which act (ii) three abiotic and biotic landscape processes associated with (iii) five MLE, all being impacted by (iv) four human activities and (v) two external conditions. It must be noted that the first four MLE are those directly related with the targeted ecosystem services, i.e., soil material for water erosion control, surface water for water regulation and toads and damselfly for biodiversity enhancement. We added "plant material" that strongly interacts with the first four MLE. The set of properties and state variables of ILE and MLE for this example can be found in Appendix 1 in Supplementary Material. It indicates that the same property of a given ILE could be linked to several MLE through their state variables, for example the habitat attractiveness of riparian borders that are linked to toads and damselflies positions, and plant material diversity and abundance.

Figure 2 shows two snapshots of the case study (located in time by arrows in Figure 1), i.e., the landscape functioning in mid-winter (Figure 2A) and in mid-summer (Figure 2B). At each period, a subset of active MLE (pictogram) embedded in ILE (mosaic elements) is considered. ILE can circulate from one element to another, following spatial connections that are defined according to the landscape processes at play (the plain arrows in Figures 2A,B). Human activities impacting ILE are represented with dotted arrows. The detailed processes presented in Figure 2 are described below.

During winter (Figure 2A) the climate is characterized by low temperatures and large amounts of rainfall. Low temperatures result in a reduced activity of the fauna and flora (biotic MLE), while the large amounts of rainfall lead to significant surface water flow (abiotic MLE). The water flow is initiated by field overland flow that erodes the topsoil of fields and riparian borders (ILE), thereby impacting the erosion control service. It also impacts the water regulation service by going into ponds or ditches (ILE), and further to a watershed outlet.

Spatial variations of water flow in the agricultural landscape are driven by a variety of conditions. Field runoff is driven by the soil infiltration capacity, which is itself modulated by the nature of soils and the occurrence of tillage operations. In turn, the water flow in ditches is driven by the slopes and roughness of ditches. The latter is related to the amount and composition of flora in the ditch, which can be modified by dredging, mowing, weeding or burning the ditches.

In summer (Figure 2B), the climate is characterized by small amounts of rainfall and high temperatures. Small amounts of rainfall do not induce any water flow (abiotic MLE) while high temperatures result in significant biotic activity (biotic MLE). The common toad and the damselfly move away from their overwintering sites (woodlands) and search for new habitats for mating and egg-laying (riparian borders).

In summer, spatial variations of toads and damselfly populations within the agricultural landscape are driven by several factors. Both organisms may use riparian ditch borders as corridors for dispersal and as shelters. The damselfly density and the number of locations occupied by toads increase faster in areas where plant cover is high, a characteristic linked to the occurrence of ditch dredging, mowing, weeding or burning. The attractiveness of ponds for mating depends on water flow reaching the pond in the previous year.

The functioning of the agricultural landscape is thus characterized by several interactions between biotic and abiotic processes and human activities (Figure 2C). Three of them can be cited as examples:

(i) seed dispersal in winter, due to surface runoff, increases the density of standing plants in the ditches, which will further affect ditch roughness and subsequently limit water flow;

(ii) water flow in winter induces topsoil erosion in fields that may settle by sedimentation in the neighboring ditches and 


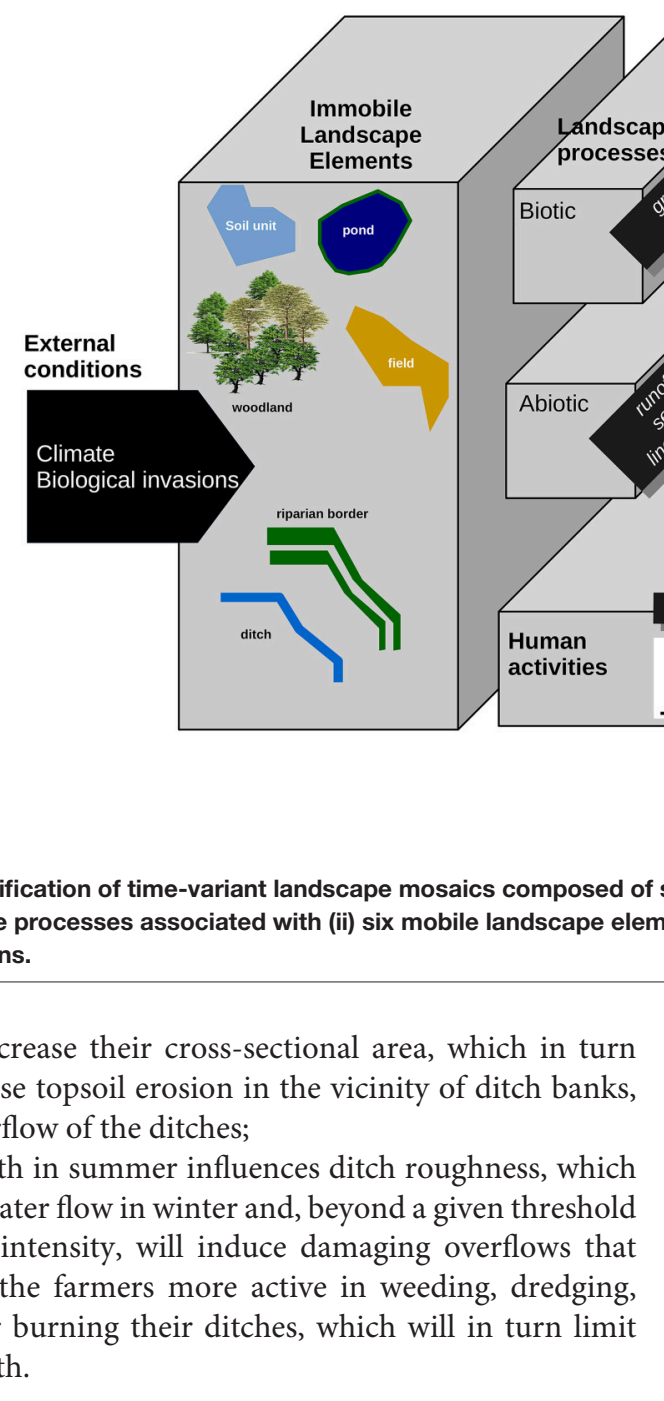

FIGURE 1 | Classification of time-variant landscape mosaics composed of six immobile landscape elements (ILE) on which act (i) three biotic and four abiotic landscape processes associated with (ii) six mobile landscape elements (MLE), all being impacted by (iii) four human activities and (iv) two external conditions.

thereby decrease their cross-sectional area, which in turn may increase topsoil erosion in the vicinity of ditch banks, due to overflow of the ditches;

(iii) plant growth in summer influences ditch roughness, which will limit water flow in winter and, beyond a given threshold of rainfall intensity, will induce damaging overflows that will make the farmers more active in weeding, dredging, mowing or burning their ditches, which will in turn limit plant growth.

\section{FURTHER CAPACITIES OF THE FRAMEWORK}

Our conceptual framework allows us to represent a complex landscape functioning that includes biotic, abiotic processes and human activity, with a limited number of concepts (ILE and MLE with their associated properties and state variables, respectively). It is the first step of a modeling approach that would take into account the whole complexity described above with a balanced and common representation of biotic, abiotic and human processes that act in this agricultural landscape. The consideration of ILE and MLE in this framework allows a subsequent implementation following an object-oriented programming strategy, i.e., objects defined by classes, and classes inheriting attributes and implementation from pre-existing classes called base classes.

Another added value of this approach is that biotic and abiotic processes are seen through a common framework that is spatially explicit, and sufficiently non-restrictive to withstand retroactions between processes. This approach differs from the current two ways of coupling multiple processes in landscape models that are found in the literature:

(i) an unbalanced representation of biotic, abiotic processes and human activities, due to the core discipline of the modelers (Freeman et al., 2001; Gibbins et al., 2001; Nathan et al., 2011; Pazos et al., 2013), which results in representing one-sided relations only and neglecting possible feedbacks;

(ii) a balanced but oversimplified representation of the systems, using metamodels for example (Harrison et al., 2014). The latter approach was based on a resolution and an extent not able to cope with landscape mosaics of human practices, and therefore cannot simulate emerging properties of the system at landscape level.

A third advantage of our framework is that it matches the current landscape modeling strategies that have been followed by the different disciplines. For example, the framework could challenge our old representations of processes through physical or ecological models. In the example described above, the state variables of biotic populations could be modeled as continuous quantities following mass conservation laws (an Eulerian representation) whereas state variables of abiotic matters could be modeled as discrete elements by adopting an object-oriented view (a Lagrangian representation).

\section{FUTURE CHALLENGES}

Developing and assessing the applicability of this framework is the first step toward integrating landscape modeling approaches. 
A
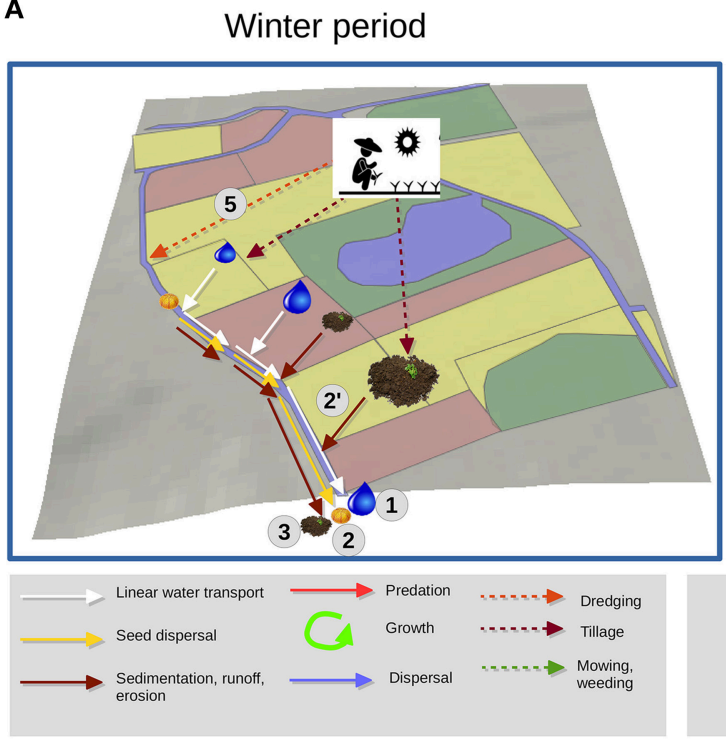

B

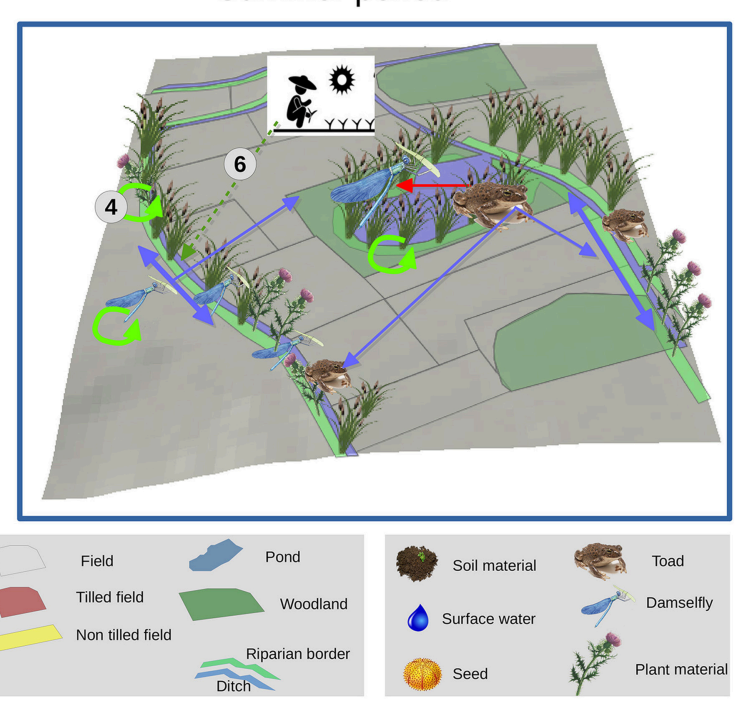

C

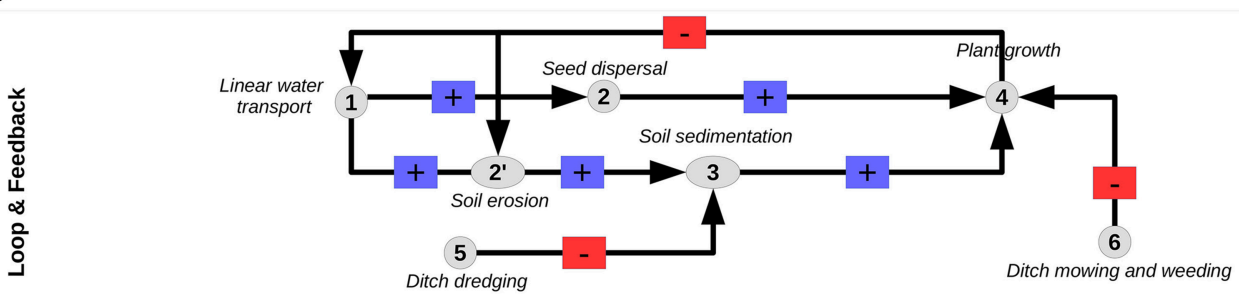

FIGURE 2 | Spatial organization of ILE and MLE during winter (A) and summer (B), with processes indicated by arrows, and positive and negative interactions between processes and between human activities and processes (C). The spatial variability at a given time is represented through variations in state variables attached to MLE (represented by the size of pictogram in $\mathbf{A}, \mathbf{B}$ ), and variations in landscape properties attached to ILE (differences in colors and patterns).

A full implementation of the framework will require five important challenges to be met.

\section{Model Design Challenge}

Our conceptual framework should be considered as an initial step toward the integration of landscape modeling approaches. It leaves open a wide range of modeling options that should be addressed by the modeler. The test example presented here illustrates the types of choices that must be made to model an agricultural landscape with a given set of objectives in mind. The identification and selection of landscape processes, ILE and their properties, external conditions, MLE and their state variables, and interrelations will likely differ according to the modelers' objectives and must be clearly defined and justified. Moreover, the numerical complexity and cost of a full coupling of processes, as well as the search for parsimony must be considered. A wide range of studies have simulated complex human-environment interactions that are highly constrained by the spatial and temporal scales chosen in the agent-based platforms, as for example grid base space segmentation and regular time steps (Parker et al., 2003; Matthews, 2006; Caron-Lormier et al., 2009; Schreinemachers and Berger, 2011). There is also a strong unbalance between the considered processes, depending on the core disciplines of the modelers, such as sociology for agentbased models, ecology (Gibbins et al., 2001; Vinatier et al., 2012) or hydrology (Thomas et al., 2014). Moreover, hierarchical models are rarely considered to simulate landscape processes acting at different spatio-temporal scales.

\section{Computational Challenge}

Given the complexity discussed above, it becomes clear that landscape scientists alone cannot translate the present conceptual framework into operational landscape models. We advocate the emergence of landscape modeling platforms (see Sklar, 2007; Verburg and Overmars, 2009; Fabre et al., 2010; Grignard et al., 2013) that will enable an individual scientist involved in the study of a specific landscape process to model its interaction with other landscape processes without being an expert in all landscape disciplines and without being an expert programmer.

\section{Space-Time Challenge}

How space and time are discretized will greatly affect the model behavior. Discretization in space should basically account for the geometry of ILE that is considered important for a 
given landscape process. However, it may be necessary in some instances to represent the variability of properties within the ILE and to discretize them. This can arise when the ILE heterogeneities in the landscape are very large or when the sole segmentation of ILE leads to too abrupt spatial variations in state variables, generating numerical instabilities in the modeling approaches. Similarly, the properties of time discretization reflect the choices made to account for the dynamics of landscape mosaics and the impact of human activities. Whatever the selected discretization, down or upscaling geostatistical procedures for transferring information between irregularly shaped space-time cells should be developed to ensure the appropriate flow of information within the system.

\section{Data Challenge}

The implementation of the proposed conceptual framework in real landscape situations may require a substantial amount of data. Landscape sciences have accumulated a huge repository of knowledge on landscape processes and their interrelations. Despite this, data requirements will remain important, and there is a need for long-term experiments and monitoring at the landscape level, as is currently performed in long-term socioecological research platforms, "zone ateliers" and SOERE (Mauz et al., 2012). Beside, landscape modelers require the development of spatial data infrastructures providing basic spatial data for landscape modeling (e.g., digital elevation models, land use maps, etc.) in order to define important landscape elements of the study region and estimate their properties.

\section{Knowledge Challenge}

Although this paper insists on the necessity to develop a pluridisciplinary framework for modeling landscape services, it is also important to stress that the definition of landscape processes and MLE, as well as their relation to ILE, suffers from knowledge gaps. This is particularly true for the conceptual representation of biotic processes in landscapes, whose study is more recent

\section{REFERENCES}

Arnold, J. G. (1990). SWRRB: A Basin Scale Simulation Model for Soil and Water Resources Management. College Station, TX: Texas A \& M University Press.

Bengtsson, J., Ahnstrom, J., and Weibull, A. C. (2005). The effects of organic agriculture on biodiversity and abundance: a meta-analysis. J. Appl. Ecol. 42, 261-269. doi: 10.1111/j.1365-2664.2005.01005.x

Benoît, M., Davide, R., Elisa, M., Anna, C. M., Mariassunta, G., Sylvie, L., et al. (2012). Landscape agronomy: a new field for addressing agricultural landscape dynamics. Landsc. Ecol. 27, 1385-1394. doi: 10.1007/s10980-0129802-8

Beven, K. J., and Kirkby, M. J. (1979). A physically based, variable contributing area model of basin hydrology. Hydrol. Sci. Bull. 24, 43-69. doi: $10.1080 / 02626667909491834$

Burel, F., and Baudry, J. (2003). Landscape Ecology: Concepts, Methods, and Applications. Enfield, NH: CRC Press.

Caron-Lormier, G., Bohan, D. A., Hawes, C., Raybould, A., Haughton, A. J., and Humphry, R. W. (2009). How might we model an ecosystem? Ecol. Modell. 220, 1935-1949. doi: 10.1016/j.ecolmodel.2009.04.021

Costanza, R., Arge, R. D., Groot, R. D., Farber, S., Grasso, M., Hannon, B., et al. (1997). The value of the world's ecosystem services and natural capital. Nature 387, 253-260. doi: 10.1038/387253a0 than that of abiotic processes. Contrasting paradigms based on dispersal or niche concepts have been proposed to explain metacommunity assemblages, but there is a need to test these paradigms against empirical data generated from a large number of case studies (Logue et al., 2011).

We are also faced with a lack of generic laws that are needed to model the link between human activities (including agricultural practices) and the properties of the ILE. We need to develop conceptual frameworks that are more accurate than those prevailing in comparative studies of agricultural landscapes, which use broad classes of agricultural systems such as organic and conventional systems (e.g., reviews in Bengtsson et al., 2005; Letourneau and Bothwell, 2008; Garratt et al., 2011).

\section{AUTHOR CONTRIBUTIONS}

FV contributed to the redaction of the first draft. PL, MV contributed to the description of the framework. SP, CL, YB, and FL contributed to the redaction of the introduction and conclusion.

\section{ACKNOWLEDGMENTS}

The authors thank François Massol, David Bohan, JeanChristophe Fabre and the Payote network for helpful advice on earlier versions of the manuscript. They also thank the two anonymous referees for helpful comments and suggestions on the manuscript. INRA and its Ecoserv metaprogram are gratefully acknowledged for funding the work presented in this paper.

\section{SUPPLEMENTARY MATERIAL}

The Supplementary Material for this article can be found online at: http://journal.frontiersin.org/article/10.3389/fenvs. 2016.00006

Coulouma, G. (2008). Carte Des Sols de La Basse Vallée de La Peyne, échelle 1:25000ème: Notice. Montpellier: UMR LISAH.

David, M., Follain, S., Ciampalini, R., Le Bissonnais, Y., Couturier, A., and Walter, C. (2014). Simulation of medium-term soil redistributions for different land use and landscape design scenarios within a vineyard landscape in mediterranean France. Geomorphology 214, 10-21. doi: 10.1016/j.geomorph.2014.03.016

Davies, B., Biggs, J., Williams, P., Whitfield, M., Nicolet, P., Sear, D., et al. (2008). Comparative biodiversity of aquatic habitats in the european agricultural landscape. Agric. Ecosyst. Environ. 125, 1-8. doi: 10.1016/j.agee.2007.10.006

Fabre, J. C., Louchart, X., Colin, F., Dagès, C., Moussa, R., Rabotin, M., et al. (2010). OpenFLUID: A Software Environment for Modelling Fluxes in Landscapes. Montpellier: Quae. Available online at: http://www.openfluidproject.org/index.php? page $=$ welc\&lang $=\mathrm{fr}$

FAO (2011). FAOSTAT. Available online at: http://faostat3.fao.org/home/E

Freeman, M. C., Bowen, Z. H., Bovee, K. D., and Irwin, E. R. (2001). Flow and habitat effects on juvenile fish abundance in natural and altered flow regimes. Ecol. Appl. 11, 179-190. doi: 10.1890/1051-0761(2001)011[0179:FAHEOJ]2.0.CO;2

Garratt, M. P. D., Wright, D. J., and Leather, S. R. (2011). The effects of farming system and fertilisers on pests and natural enemies: a synthesis of current research. Agric. Ecosyst. Environ. 141, 261-70. doi: 10.1016/j.agee.2011. 03.014 
Gibbins, C. N., Soulsby, C., Jeffries, M. J., and Acornley, R. (2001). Developing ecologically acceptable river flow regimes: a case study of kielder reservoir and the kielder water transfer system. Fish. Manag. Ecol. 8, 463-485. doi: 10.1046/j.1365-2400.2001.00274.x

Grayson, R. B., Blöschl, G., Western, A. W., and McMahon, T. A. (2002). Advances in the use of observed spatial patterns of catchment hydrological response. Adv. Water Resour. 25, 1313-1334. doi: 10.1016/S0309-1708(02) 00060-X

Grignard, A., Taillandier, P., Gaudou, B., An Vo, D., Huynh, N. Q., and Drogoul, A. (2013). "GAMA 1.6: advancing the art of complex agent-based modeling and simulation," in PRIMA 2013: Principles and Practice of Multi-Agent Systems, Lecture Notes in Computer Science, Vol. 8291, eds G. Boella, E. Elkind, B. Tony Roy Savarimuthu, F. Dignum, and M. K. Purvis (Berlin; Heidelberg: Springer), 117-131. Available online at: http://link.springer.com/chapter/10.1007/978-3642-44927-7_9. doi: 10.1007/978-3-642-44927-7_9

Harrison, P. A., Dunford, R., Savin, C., Rounsevell, M. D. A., Holman, I. P., Kebede, A. S., et al. (2014). Cross-sectoral impacts of climate change and socioeconomic change for multiple, european land- and water-based sectors. Clim. Change 128, 279-292. doi: 10.1007/s10584-014-1239-4

Herzon, I., and Helenius, J. (2008). Agricultural drainage ditches, their biological importance and functioning. Biol. Conserv. 141, 1171-1183. doi: 10.1016/j.biocon.2008.03.005

Letourneau, D. K., and Bothwell, S. G. (2008). Comparison of organic and conventional farms: challenging ecologists to make biodiversity functional. Front. Ecol. Environ. 6, 430-438. doi: 10.1890/070081

Levavasseur, F., Bailly, J. S., Lagacherie, P., Colin, F., and Rabotin, M. (2012). Simulating the effects of spatial configurations of agricultural ditch drainage networks on surface runoff from agricultural catchments. Hydrol. Process. 26, 3393-3404. doi: 10.1002/hyp.8422

Levavasseur, F., Lagacherie, P., Bailly, J. S., Biarnès, A., and Colin, F. (2015). Spatial modeling of man-made drainage density of agricultural landscapes. J. Land Use Sci. 10, 256-276. doi: 10.1080/1747423X.2014.884644

Logue, J. B., Mouquet, N., Peter, H., and Hillebrand, H. (2011). Empirical approaches to metacommunities: a review and comparison with theory. Trends Ecol. Evol. 26, 482-491. doi: 10.1016/j.tree.2011.04.009

Matthews, R. (2006). The People and Landscape Model (PALM): towards full integration of human decision-making and biophysical simulation models. Ecol. Modell. 194, 329-343. doi: 10.1016/j.ecolmodel.2005.10.032

Matthews, R. B., Gilbert, N. G., Alan Roach, J., Polhill, G., and Gotts, N. M. (2007). Agent-based land-use models: a review of applications. Landsc. Ecol. 22, 1447-1459. doi: 10.1007/s10980-007-9135-1

Mauz, I., Peltola, T., Granjou, C., van Bommel, S., and Buijs, A. (2012). How scientific visions matter: insights from three long-term socio-ecological research (LTSER) platforms under construction in Europe. Environ. Sci. Policy 19-20, 90-99. doi: 10.1016/j.envsci.2012.02.005

Nathan, R., Katul, G. G., Bohrer, G., Kuparinen, A., Soons, M. B., Thompson, S. E., et al. (2011). Mechanistic models of seed dispersal by wind. Theor. Ecol. 4, 113-132. doi: 10.1007/s12080-011-0115-3

Ovaskainen, O., and Hanski, I. (2004). From individual behavior to metapopulation dynamics: unifying the patchy population and classic metapopulation models. Am. Nat. 164, 364-377. doi: 10.1086/423151

Parker, D. C., Manson, S. M., Janssen, M. A., Hoffmann, M. J., and Deadman, P. (2003). Multi-agent systems for the simulation of land-use and land-cover change: a review. Ann. Assoc. Am. Geograph. 93, 314-337. doi: 10.1111/14678306.9302004

Pazos, G. E., Greene, D. F., Katul, G., Bertiller, M. B., and Soons, M. B. (2013). Seed dispersal by wind: towards a conceptual framework of seed abscission and its contribution to long-distance dispersal. J. Ecol. 101, 889-904. doi: 10.1111/1365-2745.12103

Pennock, D. J., and Veldkamp, A. (2006). Advances in landscape-scale soil research. Geoderma 133, 1-5. doi: 10.1016/j.geoderma.2006.03.032

Schreinemachers, P., and Berger, T. (2011). An agent-based simulation model of human-environment interactions in agricultural systems. Environ. Model. Softw. 26, 845-859. doi: 10.1016/j.envsoft.2011.02.004

Schröder, B. (2006). Pattern, process, and function in landscape ecology and catchment hydrology - how can quantitative landscape ecology support predictions in ungauged basins? Hydrol. Earth Syst. Sci. 10, 967-979. doi: 10.5194/hess-10-967-2006

Sklar, E. (2007). Software review: netlogo, a multi-agent simulation environment. Artif. Life 13, 303-311. doi: 10.1162/artl.2007.13.3.303

Sluiter, R., and Jong, S. M. (2006). Spatial patterns of mediterranean land abandonment and related land cover transitions. Landsc. Ecol. 22, 559-576. doi: 10.1007/s10980-006-9049-3

Termorshuizen, J. W., and Opdam, P. (2009). Landscape services as a bridge between landscape ecology and sustainable development. Landsc. Ecol. 24, 1037-1052. doi: 10.1007/s10980-008-9314-8

Thomas, R. E., Johnson, M. F., Frostick, L. E., Parsons, D. R., Bouma, T. J., Dijkstra, J. T., et al. (2014). Physical modelling of water, fauna and flora: knowledge gaps, avenues for future research and infrastructural needs. J. Hyd. Res. 52, 311-325. doi: 10.1080/00221686.2013.876453

Tilman, D., and Kareiva, P. (1997). Spatial Ecology: The Role of Space in Population Dynamics and Interspecific Interactions. Monographs in Population Biology. Princeton, NJ: Princeton University Press.

Turner, M. G. (2005). Landscape ecology: what is the state of the science? Ann. Rev. Ecology, Evol. Syst. 36, 319-344. doi: 10.1146/annurev.ecolsys.36.102003.152614

Verburg, P. H., and Overmars, K. P. (2009). Combining top-down and bottom-up dynamics in land use modeling: exploring the future of abandoned farmlands in europe with the dyna-CLUE model. Landsc. Ecol. 24, 1167-1181. doi: 10.1007/s10980-009-9355-7

Vinatier, F., Gosme, M., and Valantin-Morison, M. (2012). A tool for testing integrated pest management strategies on a tritrophic system involving pollen beetle, its parasitoid and oilseed rape at the landscape scale. Landsc. Ecol. 27, 1421-1433. doi: 10.1007/s10980-012-9795-3

Conflict of Interest Statement: The authors declare that the research was conducted in the absence of any commercial or financial relationships that could be construed as a potential conflict of interest.

Copyright (C) 2016 Vinatier, Lagacherie, Voltz, Petit, Lavigne, Brunet and Lescourret. This is an open-access article distributed under the terms of the Creative Commons Attribution License (CC BY). The use, distribution or reproduction in other forums is permitted, provided the original author(s) or licensor are credited and that the original publication in this journal is cited, in accordance with accepted academic practice. No use, distribution or reproduction is permitted which does not comply with these terms. 